\title{
Rat strain-dependent susceptibility to ischemia-induced retinopathy associated with retinal vascular endothelial growth factor regulation
}

\author{
Kangmo Lu ${ }^{1,2}$, Yuehua Zhou ${ }^{1,3}$, Ken Kaufman ${ }^{3}$, Robert Mott ${ }^{1}$ and Jian-xing Ma ${ }^{1}$ \\ 1Department of Medicine Endocrinology, University of Oklahoma Health Sciences Center, Oklahoma City, Oklahoma 73104, USA \\ ${ }^{2}$ Department of Genetics, School of Medicine, Yale University, New Haven, Connecticut 06510, USA \\ ${ }^{3}$ Arthritis and Immunology Program, Oklahoma Medical Research Foundation, 825 NE 13th Street, Oklahoma City, Oklahoma 73104, USA \\ (Requests for offprints should be addressed to K Lu; Email: kangmo.lu@yale.edu)
}

\begin{abstract}
Vascular endothelial growth factor (VEGF) is a potent inflammation, vascular permeability, and angiogenic factor. Variations of the VEGFgene are implicated in the pathogenesis of diabetic retinopathy. Previous studies have shown that Brown Norway (BN) rats have higher retinal VEGF levels and more severe retinal vascular leakage than SpragueDawley (SD) rats in response to ischemia and diabetes. To investigate the molecular mechanism of vascular leakage in this animal model, F2 progeny were generated by crossbreeding BN and SD rats. Neonatal rats were exposed to hyperoxia to induce oxygen-induced retinopathy (OIR) models. The F2 rats in response to ischemia have shown a linear distribution of retinal VEGF levels, which is significantly and positively correlated to retinal vascular leakage. We identified a single nucleotide polymorphism (SNP) at upstream stimulating factor-binding site in the VEGF promoter region between $B N$ and SD rats. No differences were found in retinal vascular permeability or VEGF levels between F2 rats with $\mathrm{BN}, \mathrm{SD}$, and BN/SD alleles of VEGF SNP. The increased retinal VEGF levels are correlated to ischemia-induced retinal vascular leakage in the OIR rat model. The VEGF mRNA and promoter are not responsible for increased retinal VEGF level and vascular permeability. The up-regulation of VEGF expression activated by a yet to be identified upstream factor or mediator affecting VEGF stability may be associated with a high susceptibility to retinal vascular leakage in $B N$ rats.
\end{abstract}

Journal of Molecular Endocrinology (2007) 38, 423-432

\section{Introduction}

Retinal vascular leakage or breakdown of the bloodretinal barrier is a common pathogenic feature of diabetic retinopathy (DR) in diabetic patients and streptozotocin (STZ)-induced diabetic animal models (Gardner et al. 2002, Hikichi et al. 2002). The increased retinal vascular permeability can result in diabetic macular edema (DME) and subsequently retinal neovascularization (NV; Polkinghorne et al. 1992, Aiello et al. 1997). Retinal NV ultimately causes severe vitreous cavity hemorrhage and/or retinal detachment, resulting in vision loss.

Vascular endothelial growth factor (VEGF) is a potent mediator of vascular permeability and angiogenesis in a variety of human pathological situations. The increased VEGF levels are responsible for the retinal vascular leakage or retinal vascular hyperpermeability, and retinal NV (Aiello et al. 1998, Antonetti et al. 1999, Gardner et al. 2000, Ishida et al. 2003). A number of clinical and animal studies have shown that VEGF plays a pivotal role in normal and pathological angiogenesis, for example, the development of DR (Chiarelli et al.
2000, Caldwell et al. 2003). The up-regulated expression of retinal VEGF and its receptors correlates to retinal vascular leakage in oxygen-induced retinopathy (OIR) and STZ-induced diabetic rats (Adamis et al. 1994, Pierce $e$ al. 1995). The inhibition of VEGF and VEGF receptors has been found to prevent retinal NV in diabetic and OIR animal models (Gilbert et al. 1998, Qaum et al. 2001).

Genetic variations in the VEGF mRNA, VEGF promoter, and VEGF receptors are involved in diabetic microvascular complications (Awata et al. 2002, Ikeda 2003, Yang et al. 2003, Ray et al. 2004). The VEGF -460C polymorphism reversed from the transcriptional start site in the promoter region is associated with proliferative DR and a positive independent predictive factor for the development of proliferative DR (Ray et al. 2004). The $\mathrm{C}(-634) \mathrm{G}$ polymorphism reversed from the translational start site in the $5^{\prime}$ UTR of the VEGF gene is strongly associated with an increased risk of retinopathy (Awata et al. 2002). VEGF variants with an intact receptor binding interface inhibit VEGF-stimulated receptor phosphorylation and proliferation of human endothelial cells (Siemeister et al. 1998). 
Our recent studies have found that there is a strain difference in susceptibility to retinal vascular leakage between Brown Norway (BN) and Sprague-Dawley (SD) rats in response to ischemia and diabetes (Gao et al. 2001, 2002, Zhang et al. 2005). Under the same stress conditions, $\mathrm{BN}$ rats have higher levels of VEGF mRNA and protein with lower protein levels of pigment epithelium-derived factor (PEDF) in the retina and more severe retinal vascular leakage and $\mathrm{NV}$ than $\mathrm{SD}$ rats. However, the mRNA level of PEDF was not changed in OIR animal models. PEDF may be one of the factors affecting VEGF expression. We hypothesize that VEGF, a potent vascular permeability factor, is a candidate gene responsible for susceptibility to retinal vascular leakage in the OIR-BN model. In this study, we searched the polymorphisms of VEGF gene between BN and $\mathrm{SD}$ rats and compared the expression levels of VEGF and vascular permeability in the retina of $\mathrm{BN}, \mathrm{SD}$, and $\mathrm{F} 2$ progeny of $\mathrm{BN}$ and $\mathrm{SD}$ crossbreeding.

\section{Materials and methods}

\section{Animals}

$\mathrm{BN}$ and SD rats were purchased from Charles River Laboratories (Wilmington, MA, USA). BN males and SD females were crossbred to produce the F1 generation rats $(\mathrm{BN} / \mathrm{SD})$ with $\mathrm{BN}$ and $\mathrm{SD}$ strain rat background. To generate F2 animals, F1 BN/SD males and females were intercross-bred. Care, use, and treatment of all animals in this study were in strict agreement with the guidelines for the Care and Use of Laboratory Animals by the University of Oklahoma.

\section{Oxygen-induced retinopathy model}

The induction of OIR models was performed as described by Smith et al. with some modifications as in our previous method (Zhang et al. 2001). Briefly, newborn BN, SD, and $\mathrm{BN} / \mathrm{SD} \mathrm{F} 2$ rats were randomly assigned to experimental and control groups. On postnatal day $7(\mathrm{P} 7)$, rats were exposed to hyperoxia $\left(75 \% \mathrm{O}_{2}\right)$ for 5 days (P7-P12) and then returned to room air for 4 days (P16) to induce OIRrats because our previous studies have shown that all oxygen-treated rats on postnatal day 16 (P16) developed severe retinal vascular leakage (Zhang et al. 2005). Control rats were kept in constant normoxia conditions.

\section{Evaluation of retinal vascular permeability}

Retinal vascular permeability was quantified by measuring albumin leakage from blood vessels into the retina following the previous methods (Bhatia et al. 1998, Xu et al. 2001, Ishida et al. 2003) with modifications. The rat was anesthetized by inhalation with isoflurane. The fluorescein isothiocyanate (FITC)labeled albumin in phosphate buffer solution (PBS; $10 \mathrm{mg} / \mathrm{kg}$ body weight, Sigma) was injected into the femoral vein under microscopic inspection. After the injection, the rats were kept in room temperature for $3 \mathrm{~h}$. Then the rat chest cavity was opened and blood was collected through the right atrium. To clear the remaining intravascular FITC-albumin, each rat was perfused via the left ventricle with $50 \mathrm{ml}$ of $1 \times$ PBS ( $\mathrm{pH} 7 \cdot 4)$, which was pre-warmed to $37^{\circ} \mathrm{C}$ to prevent vasoconstriction. Immediately after the perfusion, the eyes were enucleated and the retinas were carefully dissected under an operating microscope. The retina was homogenized in $200 \mu \mathrm{l}$ PBS containing the proteinase inhibitor cocktail (Roche Diagnosis). The FITC-albumin leaked into the retina was extracted by sonication and centrifugation. The fluorescence intensity (FI) of FITC-albumin from supernatant and serum was measured at excitation wave $485 \mathrm{~nm} /$ emission wave $530 \mathrm{~nm}$ in Vallac Victor ${ }^{3}$ multilabel counter (PerkinElmer Life and Analytical Science, Turkin, Finland). Retinal protein levels in the same wells were measured in the multilabel counter at A280 and A490. The leaked FITC-albumin levels in the retina were normalized by serum fluorescence intensity and retinal protein level. Retinal vascular permeability was calculated as the following formula: Retinal FITC-albumin $(\mu \mathrm{g}) /$ serum FITC-albumin concentration $(\mu \mathrm{g} / \mu \mathrm{l}) /$ retinal protein level (A280)/circulation time. The results of retinal vascular permeability were expressed as retinal FI/ serum FI/retinal A280.

\section{ELISA for retinal VEGF levels}

The ELISA kits for rat VEGF were purchased from R\&D Systems, Inc (Minneapolis, MN, USA). The retinal samples as mentioned above were used for the measurement of VEGF levels. ELISA for VEGF was performed according to the manufacturer's instructions. The retinal VEGF levels were normalized by retinal protein levels at A280.

\section{Genomic DNA purification}

Rat genomic DNA was extracted using the salt precipitation method (Klett et al. 2004). Rat tail (about $0.5 \mathrm{~cm}$ ) was digested in $500 \mu \mathrm{l}$ lysis buffer (50 mM Tris-HCl (pH 8.0), $100 \mathrm{mM}$ EDTA, $125 \mathrm{mM}$ $\mathrm{NaCl}, 1 \% \mathrm{SDS}, 200 \mu \mathrm{g}$ Proteinase $\mathrm{K})$ at $55^{\circ} \mathrm{C}$ with rocking overnight. The saturated $\mathrm{NaCl}(200 \mu \mathrm{l})$ was added into digested solution with vigorous shaking for at least $60 \mathrm{~s}$. Mixed solution was spun down at maximal speed in top microcentrifuge for $20 \mathrm{~min}$. The supernatant was transferred to a new tube with an equal volume $100 \%$ ethanol, mixed by inversion and spun 
down. The DNA pellet was washed in $70 \%$ ethanol and suspended in $1000 \mu \mathrm{l}$ Tris-EDTA buffer. DNA concentration was quantified in Nanodrop ND-1000 spectrophotometer (NanoDrop Technologies, Inc. Wilmington, DE, USA).

\section{DNA sequencing}

The VEGF gene DNA fragments from $\mathrm{BN}, \mathrm{SD}$, and $\mathrm{F} 2$ $\mathrm{BN} / \mathrm{SD}$ rats were amplified by PCR using rat genomic DNA, Master PCR kits (Roche Diagnosis), and primer sets as shown in Table 1 . The PCR products were purified using PCR product purification kits (Roche Diagnosis). The purified DNAs were amplified using internal primers and sequencing PCR kit and were sequenced on the ABI 3730 capillary DNA sequencer by the Oklahoma Medical Research Foundation Sequencing Core.

\section{Analysis of single nucleotide polymorphism (SNP)}

The SNP of the upstream stimulating factor (USF)binding site in the VEGF promoter region between BN and SD rats was analyzed using Kaufman's method with some modifications (Kaufman et al. 2006) in the following steps. The polymorphism of USF-binding site and primer design are shown in Fig. $4 \mathrm{~A}$ and $\mathrm{B}$.

\section{Step 1: standard PCR amplification}

The DNA fragments including USF SNP of BN, SD, and $\mathrm{BN} / \mathrm{SD} \mathrm{F} 2$ rats were amplified by PCR in $5 \mu \mathrm{l}$ reaction solution which contains $5 \mathrm{ng}$ rat genomic DNA, $150 \mathrm{nM}$ USF-F and USF-R primers, and $1 \times$ Master PCR buffer. The PCR conditions were cycled as follows: $94{ }^{\circ} \mathrm{C}$ for $30 \mathrm{~s}, 60^{\circ} \mathrm{C}$ for $30 \mathrm{~s}$, and $72^{\circ} \mathrm{C}$ for 1 min for 35 cycles.

\section{Step 2: PCRs cleanup}

PCR products were treated with shrimp alkaline phosphatase (SAP) to remove excess dNTPs. SAP $(0 \cdot 2$ Unit; Roche Diagnosis) in $5 \mu \mathrm{l}$ of $50 \mathrm{mM}$ Tris- $\mathrm{HCl}$ buffer $(\mathrm{pH} 7.4)$ was added into the PCR product solution. The reaction solution was incubated at $37^{\circ} \mathrm{C}$ for $30 \mathrm{~min}$ and denatured at $70^{\circ} \mathrm{C}$ for $15 \mathrm{~min}$ to inactive the enzyme.

\section{Step 3: primer extension}

For primer extension reaction, dATP-missed dNTP was used in the PCR to stop primer extension at adenine base. USF Extension-R primer was synthesized and labeled with fluorescence IR Dye 700 by Li-Cor, Inc (Lincoln, NE, USA). The primer extension was performed in $5 \mu \mathrm{l} \mathrm{PCR}$ buffer containing $2 \mu \mathrm{l}$ SAPtreated PCR products, $0 \cdot 1 \mathrm{pmol}$ Dye 700 -labeled extension primer, $250 \mathrm{nM}$ dCTP, dGTP, and dTTP, and $1 \times$ PCR buffer. Primer extension PCR was $94^{\circ} \mathrm{C}$, 2 min for denaturing, and 10 cycles of $94^{\circ} \mathrm{C}$ for $30 \mathrm{~s}$, $65^{\circ} \mathrm{C}$ for $30 \mathrm{~s}$, and $72{ }^{\circ} \mathrm{C}$ for $30 \mathrm{~s}$.

\section{Step 4: fragmentation analysis}

The PCR products of primer extension were loaded on $15 \%$ polyacrylamide gels and analyzed on a Li-Cor 4200 automated DNA sequencing system (Li-Cor) following the manufacturer's recommendations. The genotypes of USF SNP in F2 progeny were analyzed by sequencing system software as shown in Fig. 5C.

\section{Statistical analysis}

Data are shown as mean \pm s.D. Student's $t$-test was used to determine the statistical significance of differences

Table 1 Primers of vascular endothelial growth factor gene for PCR and sequencing

\begin{tabular}{|c|c|c|}
\hline & Position & Sequences $5^{\prime}$ to $3^{\prime}$ \\
\hline \multicolumn{3}{|l|}{ Primer name } \\
\hline VEGF promoter $1290-\mathrm{F}$ & -1290 & AGT TCC CTG GCA ACA TCT GG \\
\hline VEGF promoter $1290-\mathrm{R}$ & -1271 & CCA GAT GTT GCC AGG GAA CT \\
\hline VEGF promoter $2790-\mathrm{F}$ & -2790 & TGA CCT GCT TTT GGG GGT GA \\
\hline VEGF promoter $1780-\mathrm{F}$ & -1780 & CAC TAG GGG GCG CTC GGC CA \\
\hline VEGF promoter $1761-\mathrm{R}$ & -1761 & GGC CGA GCG CCC CCT AGT GA \\
\hline VEGF promoter $2280-\mathrm{F}$ & -2280 & ACC GCT GTT ACC GGT GAG AA \\
\hline VEGF promoter $2410-\mathrm{R}$ & -2410 & GCT GAT GAG TCC GTT GAA TA \\
\hline VEGF promoter $100-\mathrm{F}$ & -100 & ATC ACG GCT GTC TTG GGA TA \\
\hline VEGF promoter $580-\mathrm{F}$ & -580 & GGT GAC TCA GGG CAG CTA T \\
\hline VEGF promoter $640-\mathrm{R}$ & -640 & CAA TGG AGC AAT GTT ATG AGG A \\
\hline VEGF promoter USF-F & -1285 & GAG CCA CAC AGG CTA AGT GTA \\
\hline VEGF promoter USF-R & -1151 & CTA GCC TAG GCT CAC AGT TCA \\
\hline VEGF 33R & 33 & CCC AAG CCT CTG CGC TTC T \\
\hline VEGF SNP1-F & 117 & GGT GAA GTT CAT GGA CGT CTA \\
\hline VEGF SNP1-R & 289 & TCT GCA TAG TGACGTTGCTCT \\
\hline
\end{tabular}


between the groups of animals. Significance was set at $P<0 \cdot 05$. The association of retinal VEGF levels with retinal vascular permeability was tested using ANOVA linear regression analysis program.

\section{Results}

\section{Increased retinal vascular permeability and VEGF} protein levels in $\mathrm{BN}$ rats in response to ischemia

Our previous studies have shown that retinal permeability is significantly increased, with a peak at P16 in OIR-BN rats, when compared with the age-matched normal control $\mathrm{BN}$ and $\mathrm{SD}$ rats. The increase in permeability is greater in OIR-BN rats than in OIR-SD rats (Zhang et al. 2005). To determine whether this susceptibility will be inherited to offspring generations, F2 progeny with $\mathrm{BN}$ and SD background was generated. Before crossbreeding of inbred BN rats and outbred SD rats, the retinal vascular permeability was assayed at $\mathrm{P} 16$ in control, OIR-BN and SD rats to confirm that the breeding $\mathrm{BN}$ rats are susceptible to retinal vascular leakage in response to ischemia. There was no difference in the basal levels of retinal vascular permeability between normal control $\mathrm{SD}$ and $\mathrm{BN}$ rats. In OIR-SD rats, retinal vascular permeability was $1 \cdot 74-$ fold higher than that in the control SD rats $(P<0.05$, $n=4$; Fig. 1A). However, retinal vascular permeability in OIR-BN rats was 4.97 -fold higher than that in the agematched control $\mathrm{BN}$ rats $(P<0 \cdot 001, n=4)$ and $2 \cdot 85$ fold higher than that in OIR-SD rats $(P<0 \cdot 001, n=4$; Fig. 1A). The results suggest that $\mathrm{BN}$ rats develop more severe vascular leakage than SD rats under the same ischemia stress.

The basal levels of retinal VEGF protein were similar in normal $\mathrm{BN}$ and SD rats. In OIR-SD rats, retinal VEGF protein levels had no significant increase over those in normal control SD rats (Fig. 1B). However, in OIR-BN rats, retinal VEGF levels were approximately tenfold higher than those in normal control $\mathrm{BN}$ and OIR-SD rats $(P<0 \cdot 001, n=4$; Fig. $1 \mathrm{~B})$.

\section{Distribution and association of retinal VEGF protein levels with retinal vascular permeability in F2 progeny BN/SD rats in response to ischemia}

To determine if retinal VEGF levels are correlated to retinal vascular permeability, the retinal vascular permeability and VEGF contents at P16 were quantified in $97 \mathrm{~F} 2 \mathrm{SD} / \mathrm{BN}$ rats exposed to $75 \%$ oxygen for 5 days and to room air for 4 days. The retinal VEGF contents in oxygen-treated $\mathrm{F} 2$ rats had a linear distribution in the range of $22-666 \mathrm{pg} / \mathrm{mg}$ protein (Fig. 2A). The retinal VEGF levels were significantly positively correlated to retinal vascular permeability in $\mathrm{F} 2 \mathrm{SD} / \mathrm{BN}$ rats in
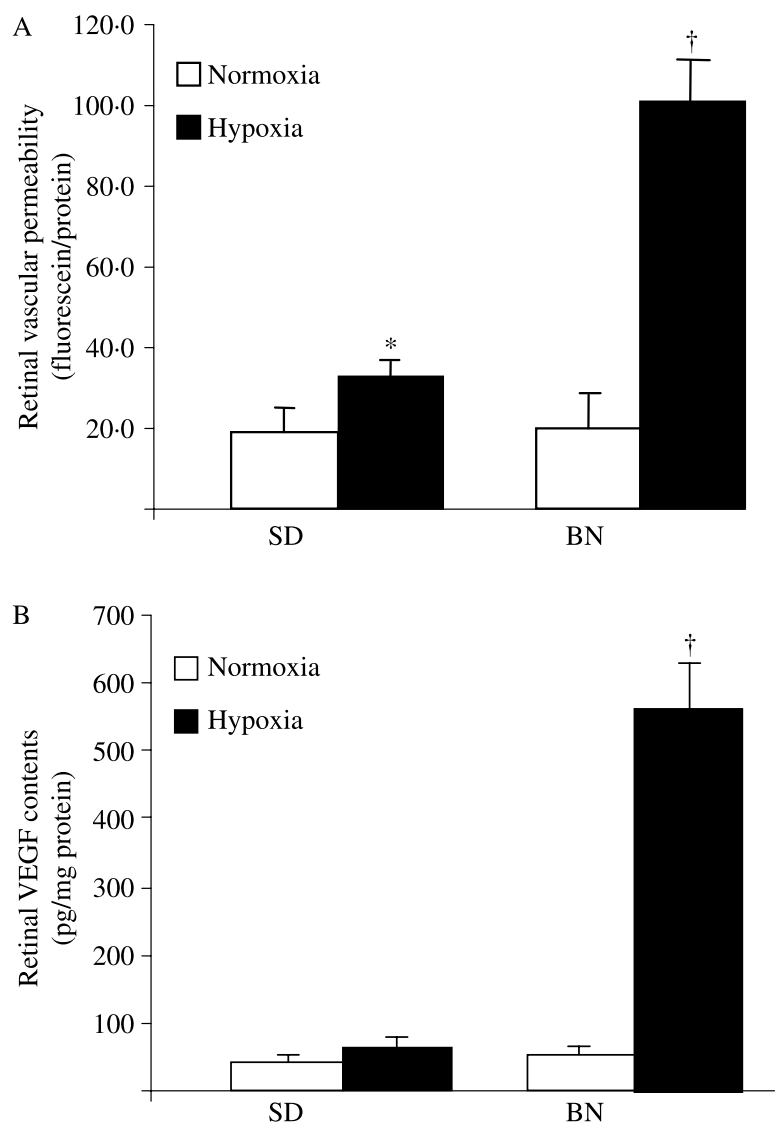

Figure 1 Retinal vascular permeability (A) and VEGF levels (B) in OIR-BN and -SD rats. (A) The retinal vascular permeability was performed in normal control and OIR-SD and -BN rats at P16 and expressed as ng FITC-albumin/mg retinal protein (mean \pm s.D., $n=4)$. (B) The retinal VEGF levels were measured by ELISA, normalized by retinal protein, and expressed as $\mathrm{pg} / \mathrm{mg}$ protein (mean \pm s.D., $n=4)$. Values significantly higher than the agematched normal control are indicated by ${ }^{\star} P<0.05$ and ${ }^{\dagger} P<0.001$.

response to ischemia $(n=97, R=0.7575, P<0 \cdot 001$; Fig. 2B). The F2 rats with extreme high retinal vascular permeability had approximately fivefold higher retinal VEGF contents than in those with extreme low retinal vascular permeability (Fig. 3A and B).

\section{Polymorphism of the VEGF promoter region between $B N$ and SD rat strains}

Since retinal VEGF contents were significantly associated with retinal vascular leakage in oxygen-treated $\mathrm{F} 2$ $\mathrm{BN} / \mathrm{SD}$ rats, it is proposed that $V E G F$ be one of the candidate genes responsible for susceptibility to vascular leakage in OIR-BN rats. First, we searched the rat sequence database (http://rgd.mcw.edu/tool-entry. shtml and http://www.ncbi.nlm.nih.gov/) to determine if there is any polymorphism of the VEGF gene between $\mathrm{SD}$ and $\mathrm{BN}$ rat strains. There are two 

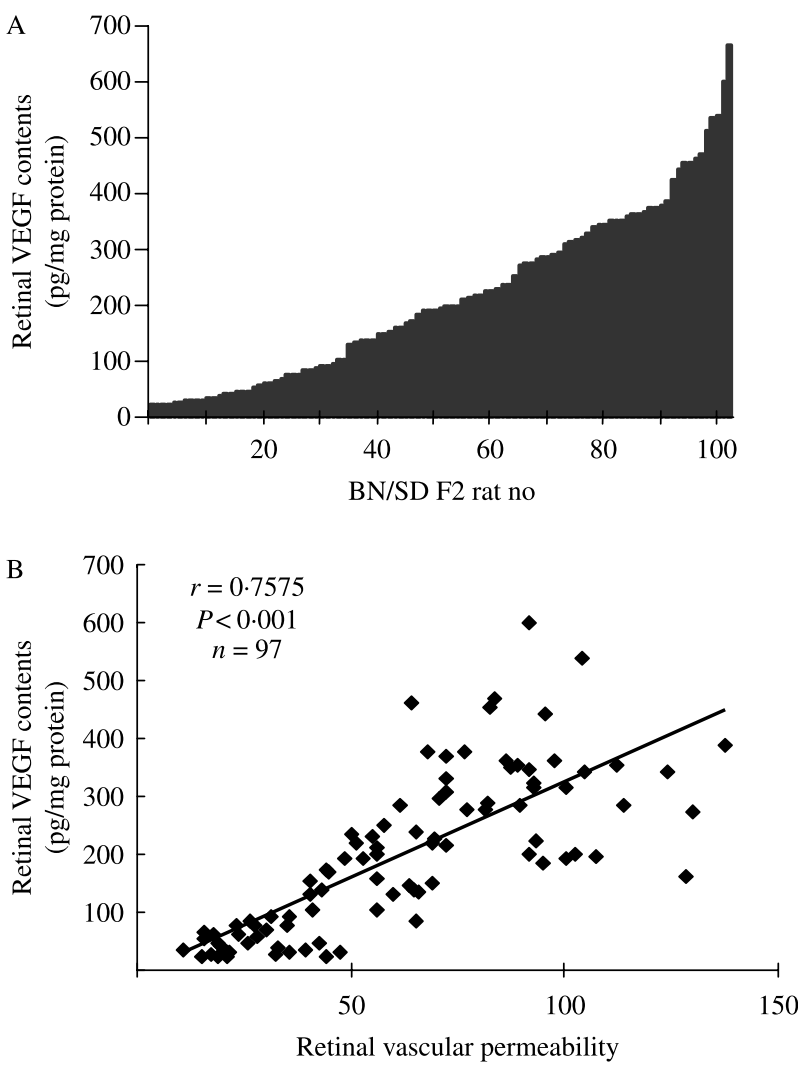

Figure 2 Distribution and correlation of retinal VEGF levels with retinal vascular permeability in OIR F2 BN/SD rats. (A) The OIR F2 rats show a continuous distribution of retinal VEGF levels. (B) Retinal vascular permeability ( $X$-axis) was plotted against retinal VEGF levels ( $Y$-axis). The permeability is expressed as FITC-albumin/mg retinal protein. The correlation between VEGF levels and permeability was analyzed by linear regression $(n=97$, $r=0.7575, P<0.001)$

SNPs (rs8152485 and rs8148303) of the VEGF gene between $\mathrm{BN}$ and $\mathrm{SD}$ rat strains according to the existing information in the database (http://www.ncbi.nlm.nih. gov/entrez/query.fcgi? $\mathrm{CMD}=$ search $\& \mathrm{DB}=\mathrm{snp})$. The code of VEGF SNP (rs8148303, A/G) does not change the amino acid residue. Another VEGF SNP $(\mathrm{rs} 8152485)$ is $\mathrm{A} / \mathrm{G}(\mathrm{BN} / \mathrm{SD})$ at 209 of the VEGF mRNA sequence from transcription initiation site, which causes amino acid substitution, tyrosine (Tyr)/ cysteine (Cys) (BN/SD) at position 70 of the peptide sequence. Different from the GenBank information, we did not detect any polymorphism of the entire coding region of the VEGF mRNA between breeding $\mathrm{BN}$ and SD rats by amplifying and sequencing the VEGF cDNA from $\mathrm{BN}$ and SD rats.

In order to determine whether there is any polymorphism in the rat VEGF promoter region, a $2.3 \mathrm{~kb}$ fragment of the VEGF promoter was amplified by PCR from the $\mathrm{BN}$ and SD rat genomic DNA and sequenced
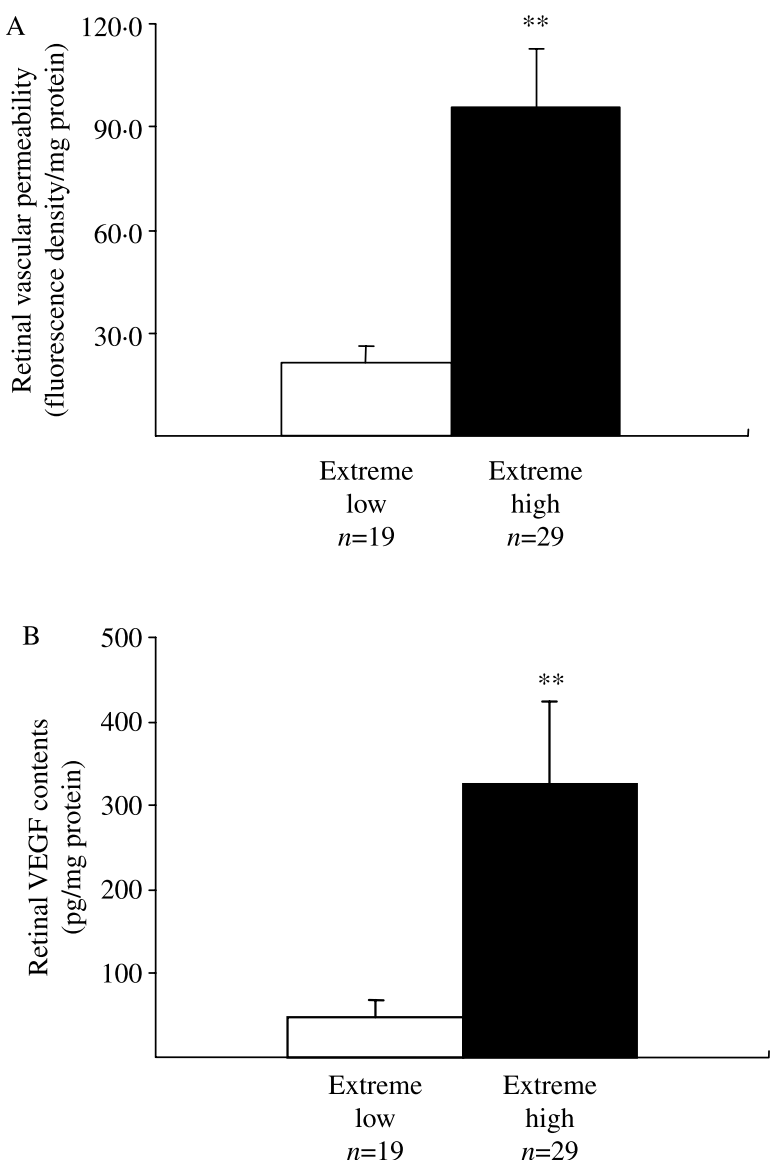

Figure 3 Retinal VEGF contents in OIR F2 BN/SD rats with extreme low and high retinal vascular permeability. To verify that high retinal VEGF contents are related to hyperpermeability, the VEGF contents were compared between 19 rats with extreme low permeability and 29 rats with extreme high permeability. The results show that the rats with extreme high permeability have five times higher VEGF contents than rats with extreme low permeability. ${ }^{\star \star} P<0 \cdot 001$ extreme low vs extreme high groups.

(Table 1). One SNP (G/T) was found at -1234 in the VEGF promoter region between $\mathrm{BN}$ and $\mathrm{SD}$ rat strains. When compared with the $\mathrm{SD}$ rat sequence, $\mathrm{BN}$ rats lack the binding site of USF in the VEGF promoter region (Fig. 4A).

\section{No differences in retinal VEGF contents and retinal vascular permeability between the BN, SD, and BN/SD alleles of the VEGF promoter SNP in F2 progeny}

To determine if the genetic variation of VEGF USF-binding site polymorphism is associated with the susceptibility to vascular leakage in the $\mathrm{BN}$ rat strain, the retinal VEGF contents and vascular permeability were measured in $\mathrm{F} 2 \mathrm{BN} / \mathrm{SD}$ rats in response to ischemia. The VEGF USF-binding site SNP was genotyped by primer extension method using genomic 
A $-1234$
B

C C T A G G
$-1234$

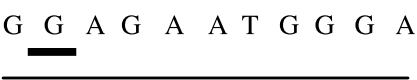

USF

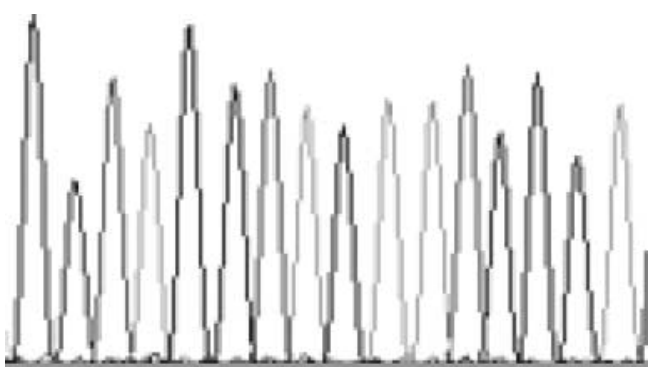

BN VEGF promoter sequence

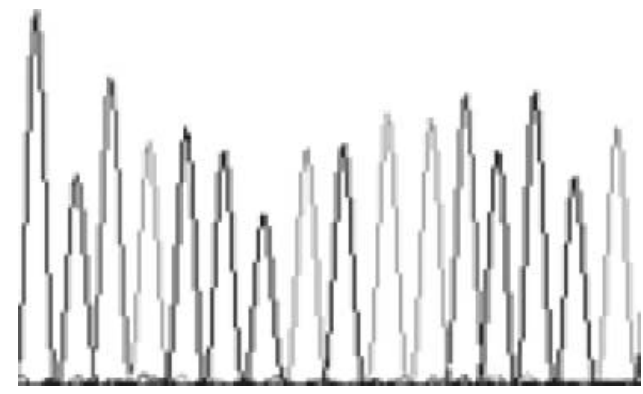

SD VEGF promoter sequence

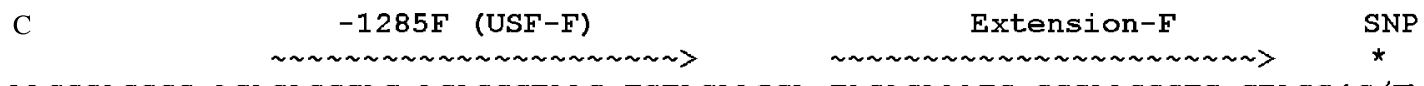

AAGgGagGgG ACAGAgCCAC ACAGGCTAAG TGTACAAGCA TAGAGAAATG GCCAAGgGTC CTAGG (G/T) AGAA-1219 TTCCCTCCCC TGTCTCGGTG TGTCCGATTC ACATGTTCGT ATCTCTTTAC CGGTTCCCAG G TCC (C/A) TCTT

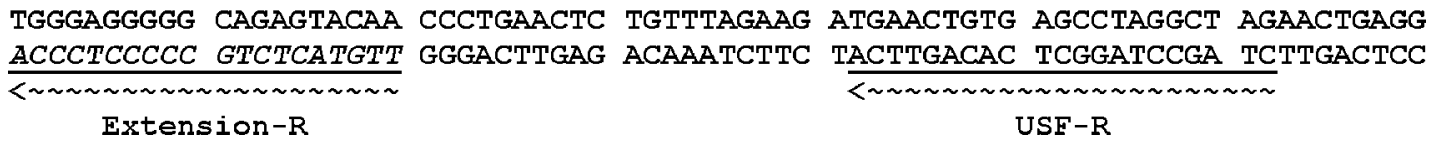

$\mathrm{USF}-\mathrm{R}$

$$
\mathrm{D}
$$
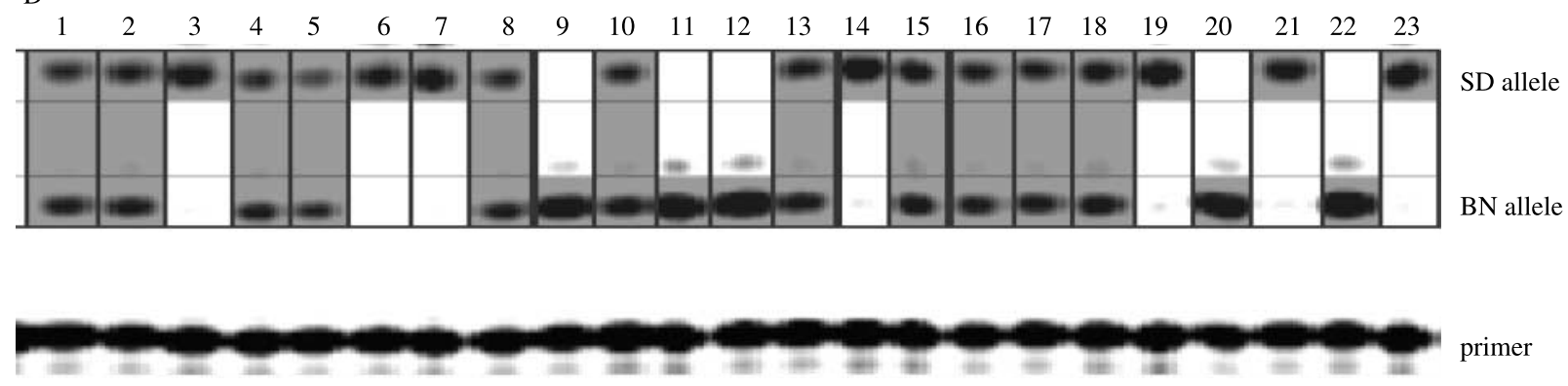

Figure 4 The polymorphisms in the VEGF promoter from SD and BN rats. (A and B) Partial sequences of the VEGF promoter in BN and SD rats respectively. The nucleotide polymorphisms are underlined at -1234 of the VEGF promoter region. The sequence (GGAGAATGGGA, underlined) is the putative binding site of USF. The variation of BN strain results in the loss of the USF-binding site. (C) The sequence and primer design for genotyping of the USF-binding site SNP. The primers, USF-F and USF-R underlined, were used to amplify 119 bp VEGF promoter fragments containing the USF-binding site SNP (G/T, italic). Extension-R underlined and italic was used for primer extension amplification. The primer extension PCR solution does not contain dATP, therefore primer extension stopped at A base of the complement strand. In the SD strain, the primer was extended for eight bases (TTCTCCCT), but in the BN strain, the primer can be extended for only four bases (TTCT) because the nucleotide base TTCT is adenine (A) in BN strain. (D) PAGE. The bottom bands represent original primer size (20 bases). The middle bands are the BN allele (24 bases) and the top bands are the SD allele (28 bases). Lane 23 is outbred SD, lane 22 is inbred BN. Lanes 9, 11, 12, and 20 show BN allele in F2 rats. Lanes 3, 6, 7, 14, 19 and 21 are SD alleles in F2 rats. Lanes 1, 2, 4, 5, 8, 10, 13, and 15-18 present heterozygous BN/SD allele in $\mathrm{F} 2$ rats.

DNA from oxygen-treated F2 rats. The retinal vascular permeability showed no significant differences between the heterozygous $\mathrm{BN} / \mathrm{SD}$, homozygous $\mathrm{BN}$, and $\mathrm{SD}$ alleles of VEGF USF SNP (Fig. 5A). The distributions of retinal VEGF contents between $\mathrm{BN}, \mathrm{SD}$, and $\mathrm{BN} / \mathrm{SD}$ allele rats were 22-666 $(n=28), 28-534 \quad(n=17)$, and $25-601 \quad(n=39) \mathrm{pg} / \mu \mathrm{g}$ protein respectively (Fig. 5B). There is no significant difference in retinal VEGF levels between the $\mathrm{BN}, \mathrm{SD}$, and $\mathrm{BN} / \mathrm{SD}$ alleles of the VEGF SNP. 

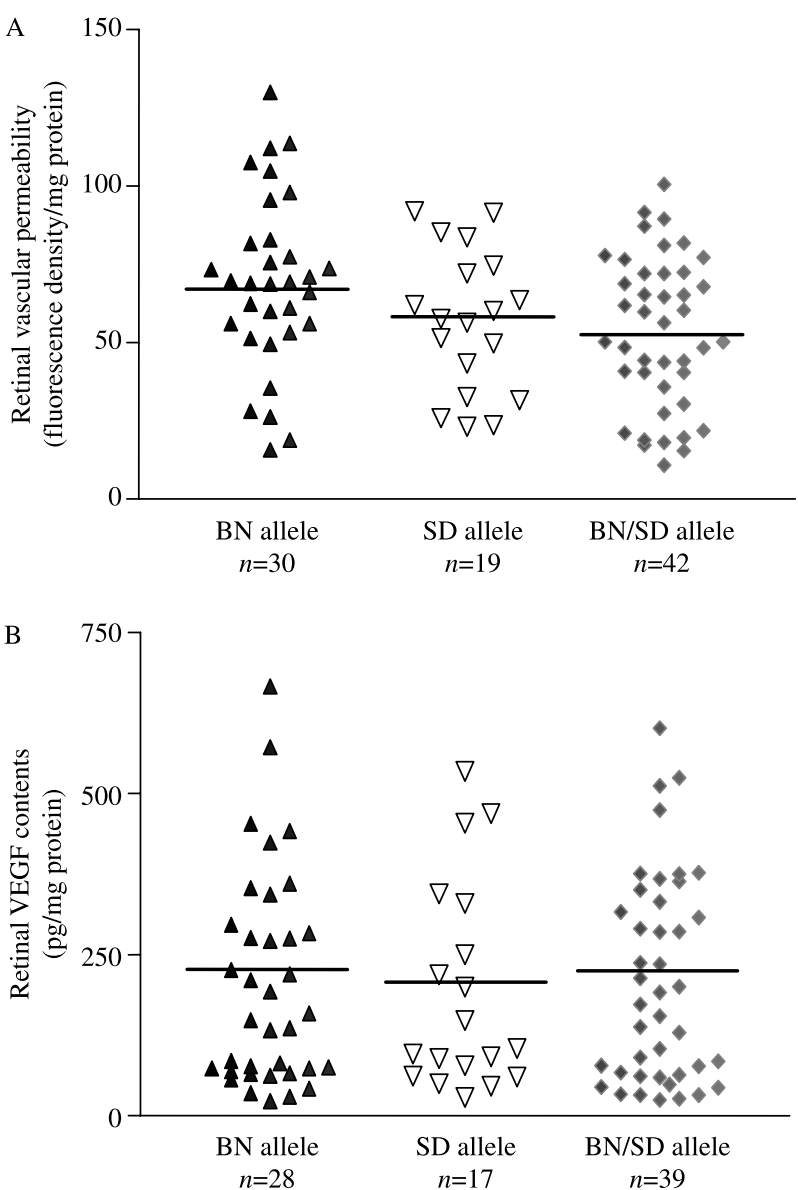

Figure 5 Retinal VEGF levels and vascular permeability in $B N$, SD, and BN/SD alleles of the VEGF USF SNP. (A) The distribution of retinal vascular permeability in $\mathrm{F} 2$ rats with homozygous $\mathrm{BN}$, homozygous SD, and heterozygous BN/SD alleles of VEGF USF SNP respectively. $\boldsymbol{\Delta}$, BN allele; $\nabla$, SD allele; $\bullet$ BN/SD allele. Horizontal lines represent the average values. The retinal vascular permeability of $\mathrm{F} 2$ rats in homozygous $\mathrm{BN}$, homozygous $\mathrm{SD}$, and heterozygous BN/SD alleles were $69 \cdot 67 \pm 25 \cdot 93$, $56.68 \pm 22.71$, and $53.25 \pm 24.21$ respectively. There is no difference of retinal vascular permeability between BN, SD, and BN/SD alleles. (B) The distribution of retinal VEGF levels in F2 rats with homozygous $\mathrm{BN}$, homozygous $\mathrm{SD}$, and heterozygous $B N / S D$ alleles of the VEGF USF SNP respectively. The retinal VEGF levels of $\mathrm{F} 2$ rats in the BN, SD, and BN/SD alleles were $242 \cdot 18 \pm 167 \cdot 88,208 \cdot 40 \pm 162 \cdot 48$, and $220 \cdot 54 \pm 160 \cdot 0$ respectively. All of the three alleles of $\mathrm{F} 2$ rats have the similar distribution in retinal vascular permeability and VEGF contents.

\section{Discussion}

DR is a chronic and progressive retinal capillary disorder. In the early stage of diabetes, retinal vascular permeability can increase even before the appearance of clinical retinopathy (Sheth 1999, Russ et al. 2001). Retinal vascular leakage and thickening of the retina lead to DME. In the late stage of DR, over-proliferation of capillary endothelial cells results in retinal NV, abnormal formation of new vessels in the retina and in the vitreous, leading to proliferative DR (PDR; Shiels et al. 1998, Stitt et al. 2000). The abnormal angiogenesis ultimately causes severe vitreous cavity bleeding and/or retinal detachment, resulting in severe vision loss. Diabetic patients have variable susceptibilities to retinopathy. The genetic variations are risk factors for DR and other vascular complications in diabetic patients, and different animal strains (Gao et al. 2001, 2002, Kitzmann et al. 2002, Chan et al. 2005, Zhang et al. 2005). Our recent studies have shown that $\mathrm{BN}$ rats are genetically more susceptible to retinal vascular leakage induced by ischemia than the SD rats (Gao et al. 2001, 2002, Zhang et al. 2005). In this study, we confirmed the previous results that OIR-BN rats at $\mathrm{P} 16$ have retinal vascular permeability approximately five times higher than that in age-matched normal control rats and approximately three times higher than the OIR-SD rats.

The molecular mechanisms for the different susceptibility to vascular leakage in response to ischemia and diabetes are not clear. Multiple genes, such as VEGF, PEDF, aldose reductase (AR), nitric oxide synthase (NOS2A and NOS3), protein kinase $\mathrm{C}-\beta$ (PKC- $\beta$ ), etc, are implicated in the pathogenesis of DR. Alterations of these growth factors and their receptors in diabetes have been identified in both experimental and clinical DR (Casey \& Li 1997, Gerhardinger et al. 2001). VEGF is a potent mediator of vascular permeability and angiogenesis, and a potent mitogen with a unique specificity for endothelial cells in a variety of human pathological conditions. The increased VEGF levels are responsible for the retinal vascular leakage or retinal vascular hyperpermeability, and retinal NV. A number of clinical and animal studies have shown that VEGF plays a pivotal role in the development of DR (Chiarelli et al. 2000, Caldwell et al. 2003). The up-regulated expression of retinal VEGF and its receptors correlate to high retinal vascular permeability (RVP) in OIR and STZ-induced diabetic rats (Adamis et al. 1994, Aiello et al. 1994, Pierce et al. 1995). It has been known that VEGF expression is stimulated by hypoxia (Gao et al. 2002, Zhang et al. 2005), high glucose levels (Iglesias-de la Cruz et al. 2002, Omori et al. 2004), advanced glycosylation end products (Yamagishi et al. 2002, Yokoi et al. 2005), IGF-I (Hellstrom et al. 2001), and angiotensin II (Funatsu et al. 2002). Inhibition of VEGF and VEGF receptors has been shown to prevent retinal NV in diabetic and OIR animal models (Gilbert et al. 1998, Qaum et al. 2001). The present study demonstrated that OIR-BN rats have retinal VEGF levels more than ten times higher than those in OIR-SD rats. OIR F2 BN/SD strain rats have a continuous distribution of retinal VEGF levels, which is positively correlated to retinal vascular permeability. The F2 rats with extreme high retinal vascular permeability have retinal VEGF 
levels five times higher than those with extreme low retinal vascular permeability.

The susceptibility for vascular leakage may be a polygenic mode of inheritance. $V E G F$ would be a strong candidate gene responsible for susceptibility to vascular leakage. It has been reported that the $\mathrm{C}(-634) \mathrm{G}$ polymorphism in the $5^{\prime} \mathrm{UTR}$ of the VEGF gene is strongly associated with an increased risk of retinopathy (Awata et al. 2002). The VEGF -460C polymorphismbased transcriptional start site is associated with proliferative DR and a positive independent predictive factor for the development of proliferative DR (Ray et al. 2004). VEGF mutants at Cys51Ser and Cys60Ser have low potency in inducing proliferation in human umbilical vein endothelial cells (Leenders et al. 2001). We hypothesize that $V E G F$ is a candidate gene responsible for the higher susceptibility to vascular leakage in OIR-BN rats. Two SNPs of the VEGF gene between $\mathrm{BN}$ and $\mathrm{SD}$ rat strains are found in the rat sequence database. One SNP (rs8148303, A/G) does not change peptide residue. Another VEGF SNP (rs8152485, A/G), located at 209 of the VEGF mRNA sequence from transcript initiation site leads to an amino acid change tyrosine (Tyr)/cysteine (Cys) (BN/ SD) at 70 of the peptide sequence. However, our studies did not detect these SNP in our breeding BN and SD rat strains. No polymorphism of the VEGF mRNA was detected in the full-length retinal VEGF cDNAs from $\mathrm{BN}$ and SD rats.

In order to determine whether VEGF promoter polymorphisms result in elevated retinal VEGF in OIR-BN rats, we amplified and sequenced $2 \cdot 3 \mathrm{~kb}$ DNA fragments of the VEGF promoter from the genomic DNAs of BN and SD rats. One SNP $(G / T)$ was identified at -1234 in the promoter region of VEGF between BN and SD rat strains. The single nucleotide mutation in the VEGF promoter in $\mathrm{BN}$ rats results in a loss of the binding site for the USF in the VEGF promoter region. USF, known as major late transcription factor, consists of two related polypeptides of $43 \mathrm{kDa}$ (USF1) and $44 \mathrm{kDa}$ (USF2), and is expressed in every tissue. USF1 regulates several genes related to glucose and lipid metabolism (Casado et al. 1999). It has been reported that USF1 is associated with the familial combined hyperlipidemia and affects the complex lipid phenotype (Pajukanta et al. 2004, Coon et al. 2005). USF proteins induce human TGF- $\beta 1$ gene activation via the glucose-response element (Weigert et al. 2004). In order to determine whether the genetic variation of the USF transcription factor-binding site in the VEGF promoter region affects VEGF expression in OIR-BN rats, we performed genotyping of USF-binding site SNP allele and measured the retinal VEGF levels and vascular permeability in $97 \mathrm{~F} 2$ rats in response to ischemia. Our studies have shown that all of the three rats with the USF SNP allele have similar distribution of retinal VEGF levels and vascular permeability. These results suggest that the USF SNP per se does not affect VEGF expression and that VEGF promoter and mRNA are not responsible for the strain difference in susceptibility to vascular leakage in OIR-BN and OIRSD rats. The other upstream and intronic transcript factors regulating the VEGF mRNA expression or mediators affecting VEGF protein stability may be associated with vascular leakage in $\mathrm{BN}$ rat strain.

In summary, OIR-BN rats have higher retinal VEGF levels and more severe retinal vascular leakage than OIR-SD rats. VEGF levels are positively correlated to vascular leakage in OIR F2 BN/SD rats. No SNP was found in the VEGF gene that is associated with different susceptibilities to vascular leakage. These observations suggest that the VEGF promoter and not mRNA is associated with increased retinal VEGF level and vascular permeability; instead, the yet to be identified upstream factors and mediators regulating VEGF expression are responsible for the genetic difference for the retinal vascular leakage. This study lays a solid ground for further elucidation of the genetic basis for the different susceptibilities to DR.

\section{Acknowledgements}

This study was supported by National Institutes of Health Grants EY015650 and EY12231, and Research Grant 7-05-CR-00 from the American Diabetes Association (ADA) and a grant from the Juvenile Diabetic Research Foundation (JDRF). The authors declare that there is no conflict of interest that would prejudice the impartiality of this scientific work.

\section{References}

Adamis AP, Miller JW, Bernal MT, D'Amico DJ, Folkman J, Yeo TK \& Yeo KT 1994 Increased vascular endothelial growth factor levels in the vitreous of eyes with proliferative diabetic retinopathy. American Journal of Ophthalmology 118 445-450.

Aiello LP, Avery RL, Arrigg PG, Keyt BA, Jampel HD, Shah ST, Pasquale LR, Thieme H, Iwamoto MA, Park JE et al. 1994 Vascular endothelial growth factor in ocular fluid of patients with diabetic retinopathy and other retinal disorders. New England Journal of Medicine 331 1480-1487.

Aiello LP, Bursell SE, Clermont A, Duh E, Ishii H, Takagi C, Mori F, Ciulla TA, Ways K, Jirousek M et al. 1997 Vascular endothelial growth factor-induced retinal permeability is mediated by protein kinase $\mathrm{C}$ in vivo and suppressed by an orally effective beta-isoformselective inhibitor. Diabetes 46 1473-1480.

Aiello LP, Gardner TW, King GL, Blankenship G, Cavallerano JD, Ferris FL III \& Klein R 1998 Diabetic retinopathy. Diabetes Care 21 $143-156$.

Antonetti DA, Lieth E, Barber AJ \& Gardner TW 1999 Molecular mechanisms of vascular permeability in diabetic retinopathy. Seminars in Ophthalmology 14 240-248. 
Awata T, Inoue K, Kurihara S, Ohkubo T, Watanabe M, Inukai K, Inoue I \& Katayama S 2002 A common polymorphism in the $5^{\prime}$-untranslated region of the VEGF gene is associated with diabetic retinopathy in type 2 diabetes. Diabetes 51 1635-1639.

Bhatia M, Saluja AK, Hofbauer B, Frossard JL, Lee HS, Castagliuolo I, Wang CC, Gerard N, Pothoulakis C \& Steer ML 1998 Role of substance $\mathrm{P}$ and the neurokinin 1 receptor in acute pancreatitis and pancreatitis-associated lung injury. PNAS 95 4760-4765.

Caldwell RB, Bartoli M, Behzadian MA, El-Remessy AE, Al-Shabrawey M, Platt DH \& Caldwell RW 2003 Vascular endothelial growth factor and diabetic retinopathy: pathophysiological mechanisms and treatment perspectives. Diabetes/Metabolism Research and Reviews 19 442-455.

Casado M, Vallet VS, Kahn A \& Vaulont S 1999 Essential role in vivo of upstream stimulatory factors for a normal dietary response of the fatty acid synthase gene in the liver. Journal of Biological Chemistry $\mathbf{2 7 4}$ 2009-2013.

Casey R \& Li WW 1997 Factors controlling ocular angiogenesis. American Journal of Ophthalmology 124 521-529.

Chan CK, Pham LN, Zhou J, Spee C, Ryan SJ \& Hinton DR 2005 Differential expression of pro- and antiangiogenic factors in mouse strain-dependent hypoxia-induced retinal neovascularization. Laboratory Investigation 85 721-733.

Chiarelli F, Santilli F \& Mohn A 2000 Role of growth factors in the development of diabetic complications. Hormone Research 53 53-67.

Coon H, Xin Y, Hopkins PN, Cawthon RM, Hasstedt SJ \& Hunt SC 2005 Upstream stimulatory factor 1 associated with familial combined hyperlipidemia, LDL cholesterol, and triglycerides. Human Genetics 117 444-451.

Funatsu H, Yamashita H, Ikeda T, Nakanishi Y, Kitano S \& Hori S 2002 Angiotensin II and vascular endothelial growth factor in the vitreous fluid of patients with diabetic macular edema and other retinal disorders. American Journal of Ophthalmology 133 537-543.

Gao G, Li Y, Zhang D, Gee S, Crosson C \& Ma J 2001 Unbalanced expression of VEGF and PEDF in ischemia-induced retinal neovascularization. FEBS Letters 489 270-276.

Gao G, Li Y, Fant J, Crosson CE, Becerra SP \& Ma JX 2002 Difference in ischemic regulation of vascular endothelial growth factor and pigment epithelium-derived factor in brown norway and sprague dawley rats contributing to different susceptibilities to retinal neovascularization. Diabetes 51 1218-1225.

Gardner TW, Antonetti DA, Barber AJ, LaNoue KF \& Nakamura M 2000 New insights into the pathophysiology of diabetic retinopathy: potential cell-specific therapeutic targets. Diabetes Technology and Therapeutics 2 601-608.

Gardner TW, Antonetti DA, Barber AJ, LaNoue KF \& Levison SW 2002 Diabetic retinopathy: more than meets the eye. Survey of Ophthalmology 47 S253-S262.

Gerhardinger C, McClure KD, Romeo G, Podesta F \& Lorenzi M 2001 IGF-I mRNA and signaling in the diabetic retina. Diabetes $\mathbf{5 0}$ 175-183.

Gilbert RE, Vranes D, Berka JL, Kelly DJ, Cox A, Wu LL, Stacker SA \& Cooper ME 1998 Vascular endothelial growth factor and its receptors in control and diabetic rat eyes. Laboratory Investigation $\mathbf{7 8}$ 1017-1027.

Hellstrom A, Perruzzi C, Ju M, Engstrom E, Hard AL, Liu JL, Albertsson-Wikland K, Carlsson B, Niklasson A, Sjodell L et al. 2001 Low IGF-I suppresses VEGF-survival signaling in retinal endothelial cells: direct correlation with clinical retinopathy of prematurity. PNAS 98 5804-5808.

Hikichi T, Mori F, Nakamura M, Shishido N, Sasaki M, Horikawa Y \& Yoshida A 2002 Inhibitory effects of bucillamine on increased blood-retinal barrier permeability in streptozotocin-induced diabetic rats. Current Eye Research 25 1-7.

Iglesias-de la Cruz MC, Ziyadeh FN, Isono M, Kouahou M, Han DC, Kalluri R, Mundel P \& Chen S 2002 Effects of high glucose and TGFbetal on the expression of collagen IV and vascular endothelial growth factor in mouse podocytes. Kidney International 62 901-913.
Ikeda T 2003 The pathogenesis of vitreoretinal diseases from the standpoint of molecular biology. Nippon Ganka Gakkai Zasshi 107 $785-812$.

Ishida S, Usui T, Yamashiro K, Kaji Y, Ahmed E, Carrasquillo KG, Amano S, Hida T, Oguchi Y \& Adamis AP 2003 VEGF164 is proinflammatory in the diabetic retina. Investigative Ophthalmology and Visual Science 44 2155-2162.

Kaufman KM KJ, Herring BJ, Adler AJ, Glenn SB, Namjou B, Frank SG, Dawson SL, Burner GR, James JA \& Harley JB 2006 Evaluation of the genetic association of the PTPN22 R620W polymorphism in familial and sporadic SLE. Arthritis Rheum 54 2533-2540.

Kitzmann A, Leske D, Chen Y, Kendall A, Lanier W \& Holmes J 2002 Incidence and severity of neovascularization in oxygen- and metabolic acidosis-induced retinopathy depend on rat source. Current Eye Research 25 215-220.

Klett EL, Lu K, Kosters A, Vink E, Lee MH, Altenburg M, Shefer S, Batta AK, Yu H, Chen J et al. 2004 A mouse model of sitosterolemia: absence of Abcg8/sterolin-2 results in failure to secrete biliary cholesterol. BMC Medicine 25.

Leenders W, van Altena M, Lubsen N, Ruiter D \& De Waal R 2001 In vivo activities of mutants of vascular endothelial growth factor (VEGF) with differential in vitro activities. International Journal of Cancer 91 327-333.

Omori K, Naruishi K, Nishimura F, Yamada-Naruishi H \& Takashiba S 2004 High glucose enhances interleukin-6-induced vascular endothelial growth factor 165 expression via activation of gp130mediated p44/42 MAPK-CCAAT/enhancer binding protein signaling in gingival fibroblasts. Journal of Biological Chemistry $\mathbf{2 7 9}$ 6643-6649.

Pajukanta P, Lilja HE, Sinsheimer JS, Cantor RM, Lusis AJ, Gentile M, Duan XJ, Soro-Paavonen A, Naukkarinen J, Saarela J et al. 2004 Familial combined hyperlipidemia is associated with upstream transcription factor 1 (USF1). Nature Genetics 36 371-376.

Pierce EA, Avery RL, Foley ED, Aiello LP \& Smith LE 1995 Vascular endothelial growth factor/vascular permeability factor expression in a mouse model of retinal neovascularization. PNAS 92 905-909.

Polkinghorne PJ, Uliss AI \& Hamilton AM 1992 Macular oedema and retinal neovascularisation in juvenile diabetics. International Ophthalmology 16 133-137.

Qaum T, Xu Q, Joussen AM, Clemens MW, Qin W, Miyamoto K, Hassessian H, Wiegand SJ, Rudge J, Yancopoulos GD et al. 2001 VEGF-initiated blood-retinal barrier breakdown in early diabetes. Investigative Ophthalmology and Visual Science 42 2408-2413.

Ray D, Mishra M, Ralph S, Read I, Davies R \& Brenchley P 2004 Association of the VEGF gene with proliferative diabetic retinopathy but not proteinuria in diabetes. Diabetes $\mathbf{5 3} 861-864$.

Russ PK, Gaylord GM \& Haselton FR 2001 Retinal vascular permeability determined by dual-tracer fluorescence angiography. Annals of Biomedical Engineering 29 638-647.

Sheth JJ 1999 Diabetes, microalbuminuria and hypertension. Clinical and Experimental Hypertension 21 61-68.

Shiels IA, Zhang S, Ambler J \& Taylor SM 1998 Vascular leakage stimulates phenotype alteration in ocular cells, contributing to the pathology of proliferative vitreoretinopathy. Medical Hypotheses $\mathbf{5 0}$ 113-117.

Siemeister G, Schirner M, Reusch P, Barleon B, Marme D \& MartinyBaron G 1998 An antagonistic vascular endothelial growth factor (VEGF) variant inhibits VEGF-stimulated receptor autophosphorylation and proliferation of human endothelial cells. PNAS 95 $4625-4629$.

Stitt AW, Bhaduri T, McMullen CB, Gardiner TA \& Archer DB 2000 Advanced glycation end products induce blood-retinal barrier dysfunction in normoglycemic rats. Molecular Cell Biology Research Communications 3 380-388.

Weigert C, Brodbeck K, Sawadogo M, Haring HU \& Schleicher ED 2004 Upstream stimulatory factor (USF) proteins induce human TGF-betal gene activation via the glucose-response element-1013/- 
1002 in mesangial cells: up-regulation of USF activity by the hexosamine biosynthetic pathway. Journal of Biological Chemistry 279 15908-15915.

Xu Q Qaum T \& Adamis AP 2001 Sensitive blood-retinal barrier breakdown quantitation using Evans blue. Investigative Ophthalmology and Visual Science $\mathbf{4 2}$ 789-794.

Yamagishi S, Inagaki Y, Okamoto T, Amano S, Koga K, Takeuchi M \& Makita Z 2002 Advanced glycation end product-induced apoptosis and overexpression of vascular endothelial growth factor and monocyte chemoattractant protein-1 in human-cultured mesangial cells. Journal of Biological Chemistry 277 20309-20315.

Yang B, Cross DF, Ollerenshaw M, Millward BA \& Demaine AG 2003 Polymorphisms of the vascular endothelial growth factor and susceptibility to diabetic microvascular complications in patients with type 1 diabetes mellitus. Journal of Diabetes and its Complications $171-6$.

Yokoi M, Yamagishi SI, Takeuchi M, Ohgami K, Okamoto T, Saito W, Muramatsu M, Imaizumi T \& Ohno S 2005 Elevations of AGE and vascular endothelial growth factor with decreased total antioxidant status in the vitreous fluid of diabetic patients with retinopathy. British Journal of Ophthalmology 89 673-675.

Zhang D, Kaufman PL, Gao G, Saunders RA \& Ma JX 2001 Intravitreal injection of plasminogen kringle 5 , an endogenous angiogenic inhibitor, arrests retinal neovascularization in rats. Diabetologia 44 $757-765$.

Zhang SX, Ma JX, Sima J, Chen Y, Hu MS, Ottlecz A \& Lambrou GN 2005 Genetic difference in susceptibility to the blood-retina barrier breakdown in diabetes and oxygen-induced retinopathy. American Journal of Pathology 166 313-321.

Received in final form 6 January 2007

Accepted 17 January 2007

Made available online as an Accepted Preprint 24 January 2007 